\title{
Simulation of energy input to solar panels
}

\author{
Platonova Elena Vladimirovna, Toropov Andrey Sergeyevich, Tulikov Alexander Nikolaevich \\ The department of electricity industry \\ Khakass Technical Institute - Branch of Siberian Federal University \\ Abakan, Russian Federation
}

\begin{abstract}
In article the review of assessment methods of the energy supplied to the surface of solar panels. Need of increase in accuracy of calculation of the solar energy entering on the panel is proved due to accounting of the additional influencing factors. A technique for estimating solar energy to the surface of panels has been developed. The degree of cloudiness influence on the solar energy input for the area under consideration is identified. Comparison of results of modeling with use of the developed technique and specialized computer programs is carried out. The comparison showed satisfactory results. Modeling of incoming solar energy for the existing solar power station showed a higher quality of the developed technique compared with specialized software. The optimal angle of inclination of the solar panel is calculated and the reduction of the incoming energy is analyzed when the angle deviates from the optimal value. The application of modeling of incoming solar energy intake to obtain daily graphs for the electricity generation of a solar power station and comparing them with daily graphs of the electrical load of the consumer is considered. Conclusions by results of researches are drawn.
\end{abstract}

Keywords: electric power; solar energy; solar radiation; solar panel; solar battery; modeling; electrical network; solar power station.

\section{INTRODUCTION}

Over the past 20 years, the world has experienced a deterioration of climatic and living conditions, climate change, the strengthening of negative natural phenomena, etc. The aforementioned problems of global scope are discussed at international climate conferences. When considering, a set of issues to improve the climatic conditions and habitat in the world, preserving the use of natural resources, accelerating the use of renewable energy sources, especially solar [1].

Development of energy saving technologies, need of decrease in harmful emissions in the environment, limited reserves of fossil fuels, growth of electricity rates, depreciation of the equipment of solar power stations and increase in their efficiency results contributes to the rapid growth of installed power of solar power stations (SPS) in the world. SPS can be divided by power as follows:

- $\quad$ small SPS with a power of less than $100 \mathrm{~kW}$;

- $\quad$ average SPS with power from $100 \mathrm{~kW}$ to $5 \mathrm{MW}$;

- $\quad$ large SPS with a power of $5 \mathrm{MW}$ or more.
Installation of solar panels (SP) small SPS on roofs and facades of buildings practices in many countries: Germany, Italy, Japan, USA, Spain, China, France, Czech Republic, Belgium, Australia and others. At the same time parallel operation of SPS with an electrical network is used. Advantages of such SPS: land, a small amount of the equipment (solar panels, the inverter), small capital investments are not required. It allows to construct such SPS to private households and the small commercial and state organizations. In the Russian Federation such types of SPS are practically not used. Mainly in our country autonomous small SPS for power supply of objects, remote from an electrical power system, are used. At the same time reservation is carried out from rechargeable batteries, gasoline or diesel generators.

The average SPS in the Russian Federation also practically does not occur. This is due to the limitation of the minimum power of power stations to $5 \mathrm{MW}$ for the sale of electricity on the wholesale market.

In the Russian Federation, large SPS are being actively built. At the beginning of 2019 there are 53 high-power SPS. The largest SPS has a power of $60 \mathrm{MW}$. The total power of SPS is $820 \mathrm{MW}$.

Obstacle of application of small SPS at parallel operation with network in the Russian Federation are considerable payback periods, difficulties of execution of documentation on the generating object and low purchase prices of the electric power $[2,3,4,5]$. The country is developing a law on the operation of small SPS in parallel with the power network in the retail electricity market.

Use of auxiliary sources on renewable resources is referred to energy saving actions. Their application allows to reduce volumes of the electric power consumed from the centralized network. Mass introduction of such power stations will allow to lower load of an electrical power system in the afternoon. Thus, it is possible to save expensive peak power. Application of such systems is of special interest for buildings of the public and private organizations working in the afternoon. In this case the developed electric power will be consumed generally on an installation site of SPS and use SPS without delivery of the electric power in network is possible. The additional incentive gives noticeable increase in electricity rates in connection with cancellation of support of consumers of small power at the expense of large consumers (the rule of «the last mile») [6, 7]. 
At design assessment of the solar energy incoming on the panels of SPS during a year is important. Power of panels, annual electricity generation, payback period of SPS depends on value of the solar energy incoming on the panel.

The assessment of annual development of SPS can be carried out with use of cards of solar insolation [8, 9], specialized computer programs [10, 11, 12], internet services [13]. Accuracy of assessment increases when accounting weather factors and features of distribution of solar radiation.

\section{THE STATEMENT OF THE PURPOSE AND RESEARCH PROBLEMS}

The purpose of the study is modeling of incoming solar energy on an inclined surface taking into account the direct and scattered radiation and also existence of cloudiness. For achievement of the specified purpose it is necessary to solve the following problems:

- To develop a method of calculation of incoming solar energy on an inclined surface;

- To estimate influence of cloudiness on size of the energy incoming on the solar panel;

- To compare modeling results with results of the existing computer programs and with real data.

\section{THE THEORETICAL PART}

The most famous are the following programs for the calculation of solar energy: PVSyst, NREL SAM, PVLib. Programs have the good accuracy of modeling, but PVSYST и NREL SAM have the largest accuracy [12]. Shortcoming is the need to purchase a license for the full use of programs. For example, comparing PVSyst and NREL SAM, it was revealed that PVSyst is a paid program. A free demo version of the program is provided for a period of 30 days, after which some functions of the program are blocked. NREL SAM is a free program. The complexity of the Russian version of the considered programs presents difficulties - all of them have an English interface. The considered programs take into account the factors influencing energy generation in the calculations.

The total solar radiation on a horizontal surface taking into account the direct and scattered radiation is determined by the formula [14], $\mathrm{kW} / \mathrm{m}^{2}$ :

$$
Q_{0}=(0,62 S+0,68) \sin h,
$$

where $S=1 \mathrm{~kW} / \mathrm{m}^{2}$ - intensity of direct solar radiation; $h-$ height of the sun above the horizon, ${ }^{\circ}$.

The height of the sun is determined by the formula [15]:

$$
h=\operatorname{asin}\left(\cos \varphi \cdot \cos \delta \cdot \cos \left(15\left(T-T_{0}\right)\right)+\sin \varphi \cdot \sin \delta\right),(2)
$$

where $\varphi$ - geographical latitude, ${ }^{\circ} ; T$ - time, hours; $T_{0}$ - real midday (for Abakan $T_{0}=12,9$ ч).

The declination of the sun in (2) is defined as [16]

$$
\delta=23,5 \sin (360 \cdot(284+n) / 365)
$$

where $n$ - the number of the day in the year.

The direction to the sun counted on the horizon from the direction to the south is called an azimuth and is determined in degrees by a formula

$$
A=\arcsin \frac{\cos \delta \cdot \sin \left(15\left(T-T_{0}\right)\right)}{\cos h} .
$$

The formula (1) does not consider cloudiness. Incoming of solar radiation on a horizontal surface taking into account the cloudiness, $\mathrm{kW} / \mathrm{m}^{2}$ :

$$
Q_{\Gamma}=Q_{0}(1-0,38 \cdot(1+K / 10) \cdot K / 10),
$$

where $K$ - cloudiness in points.

Cloudiness values from 0 to 10 points are contained in the archived records of the websites [17, 18].

By means of $[19,20]$ the formula for calculation of incoming solar radiation taking into account the cloudiness on a South-oriented inclined surface, $\mathrm{kW} / \mathrm{m}^{2}$ :

$$
Q=\frac{Q_{\Gamma}(\cos \alpha \cdot \sin h+\sin \alpha \cdot \cos h \cdot \cos A)}{\sin h},
$$

where $\alpha$-angle of inclination to the horizon, ${ }^{\circ}$.

\section{THE RESULTS OF EXPERIMENTS}

Modeling of incoming solar energy was carried out for a geographical location of Abakan of the Russian Federation. City coordinates: latitude $53,72^{\circ}$, longitude $91,43^{\circ}$. At the initial stage using (1) - (3) the incoming of total solar radiation to the inclined plane $\left(\alpha=53.72^{\circ}\right)$ were calculated without taking into account the effect of cloudiness. The modeling was carried out for one year with an interval of 0.5 hours.

Accounting of cloudiness was carried out using meteorological weather sites $[17,18]$. Meteodata contain values of cloudiness on a ten-mark scale. The cloudiness was fixed with time interval of 3 hours. Statistics of cloudiness was considered for the years 2006-2017. The data were processed and the average values for the period were found. The results represent a column of average values of cloudiness with a discretization of 3 hours.

At the next stage, using (5), the total solar radiation is incoming to the inclined plane $\left(\alpha=53,72^{\circ}\right)$ were calculated taking into account the effect of cloudiness.

Comparison of daily graphs of incoming of total solar radiation on an inclined surface taking into account and without taking note the cloudiness (fig. 1) showed considerable influence of cloudiness. The area under daily graphs at strong cloudiness is significantly lower, than in cloudless weather. Thus, taking into account the cloudiness in 
the design of a solar power station is relevant for areas with a large number of cloudy days in a year.

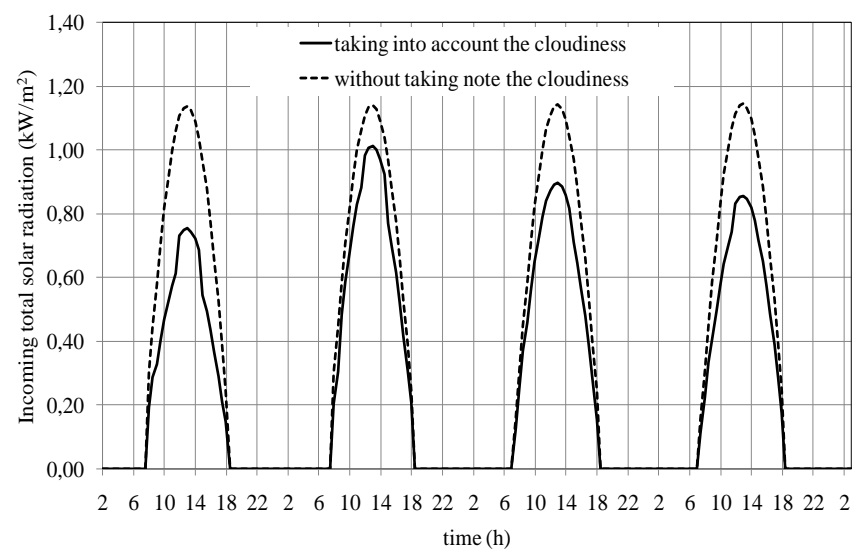

Fig. 1. Incoming total solar radiation on the inclined plane.

Comparison of graphs of incoming total solar radiation on the inclined plane $\left(\alpha=53,72^{\circ}\right)$ of the considered geographical location showed a significant decrease of incoming radiation with cloudiness. The form of graphs differs: on the lower graph of fig. 2 decrease of incoming radiation in April, May, July, October and increase of incoming radiation in September and December is observed. The sum of incoming radiation in a year on the inclined plane is $3633 \mathrm{~kW} \cdot \mathrm{h} / \mathrm{m}^{2}$ without cloudiness and $1789 \mathrm{~kW} \cdot \mathrm{h} / \mathrm{m}^{2}$ taking into account cloudiness. Thus, with cloudiness for the considered area, radiation incoming decreases on average twice in comparison with the model which is not considering cloudiness.

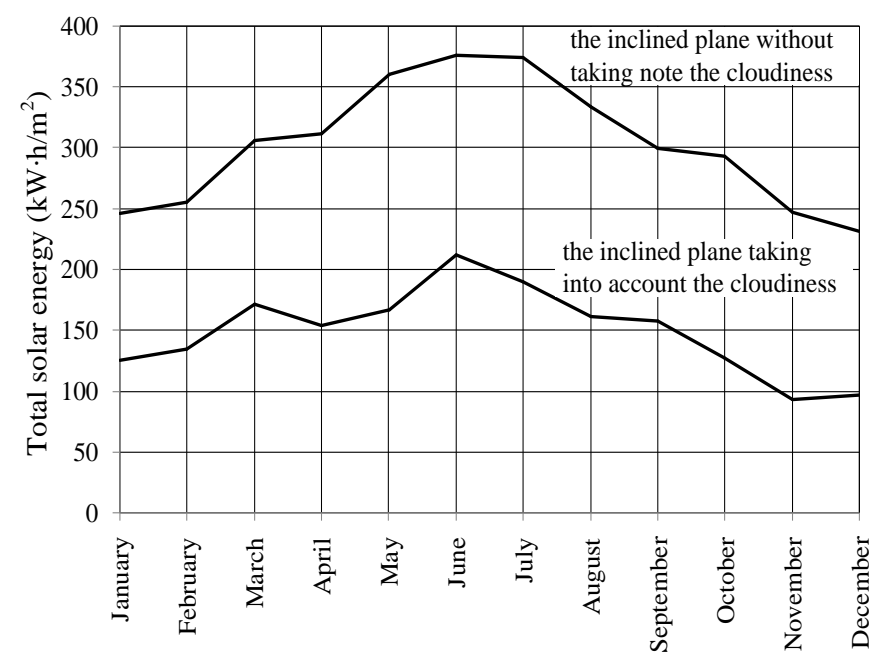

Рис. 2. Incoming total solar radiation on the inclined plane.

The analysis of annual incoming solar energy as a function of the inclination angle of the plane (fig. 3) showed the maximum value of the received energy at $\alpha=51^{\circ}$. The received value of an optimal angle differs from recommended [19] $\alpha=\varphi=53,72^{\circ}$, because there are more clear days in summer than in spring and autumn. Thus, the optimal inclination angle along with latitude is influenced by climatic features of the area. For $\alpha=\varphi=53,72^{\circ}$ the estimated incoming solar radiation in a year was $1789 \mathrm{~kW} \cdot \mathrm{h} / \mathrm{m}^{2}$, and for an optimal inclination angle $-1791 \mathrm{~kW} \cdot \mathrm{h} / \mathrm{m}^{2}$. The distinction was $0.1 \%$ that is insignificant. Thus, as optimum it is possible to consider an inclination angle equal to the latitude of the considered area in terms of a maximum of annual incoming energy.

Decrease incoming solar energy (fig. 3) is $-1.7 \%$ at change of an angle on $10^{\circ}$ from optimum value. Therefore, it is possible to change over a wide range an inclination angle of solar panels without significant decrease in the energy incoming in a year. It allows to put, for example, solar panels with a big inclination angle for the best removal of snow in winter time. If the amount of precipitation in the winter small, and in summertime is a lot of clear days, then it is necessary to reduce an inclination angle for increase in the energy received in summertime.

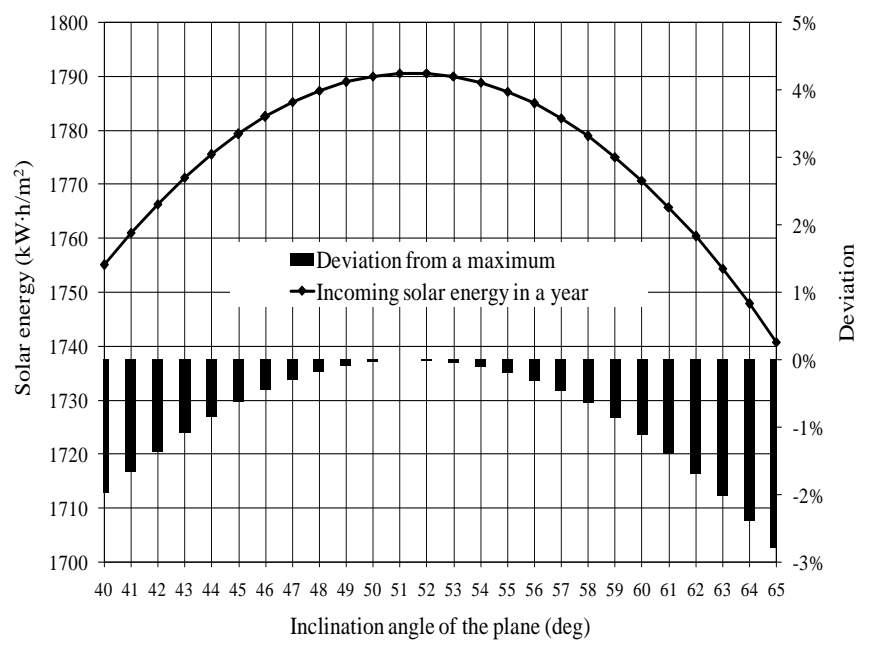

Puc. 3. The dependence of the annual incoming solar energy from the inclination angle of the plane.

Comparison of the simulation results with the results of other programs (fig. 4) gave similar values. Graphs of the PVSyst program $[10,11]$ and the online calculator [13] show rather uniform incoming solar radiation from March to August. The considered mathematical model (1)-(6) has peak of incoming solar radiation in June. In winter time of graphs are similar, but the points received using the online calculator are below other graphs.

Results of modeling were compared to real data of incoming energy on the panel of the Abakan SPS. The power station is located in the area considered in work. Statistics of development of power station is taken from the official site [21]. Information on electricity generation for 2016-2018 was processed, the average graph of monthly development in a year is received. Proportional solar radiation can consider the energy developed by power station. With use of the graph of electricity generation and characteristics of power station [21] the graph of incoming solar radiation in an installation site of power station (fig. 5) was received. Comparison of results of modeling showed strong likeness with the schedule of 
incoming solar energy of the Abakan SPS. Some distinctions are observed during the winter period: calculated values there are more real values for power plant. Decrease incoming solar energy on the panel of the Abakan SPS during the winter period has a talk increase in consumption of energy at own needs (heating of containers with electric equipment), existence of snow on panels, formation of hoarfrost. The listed factors were not considered in the model.

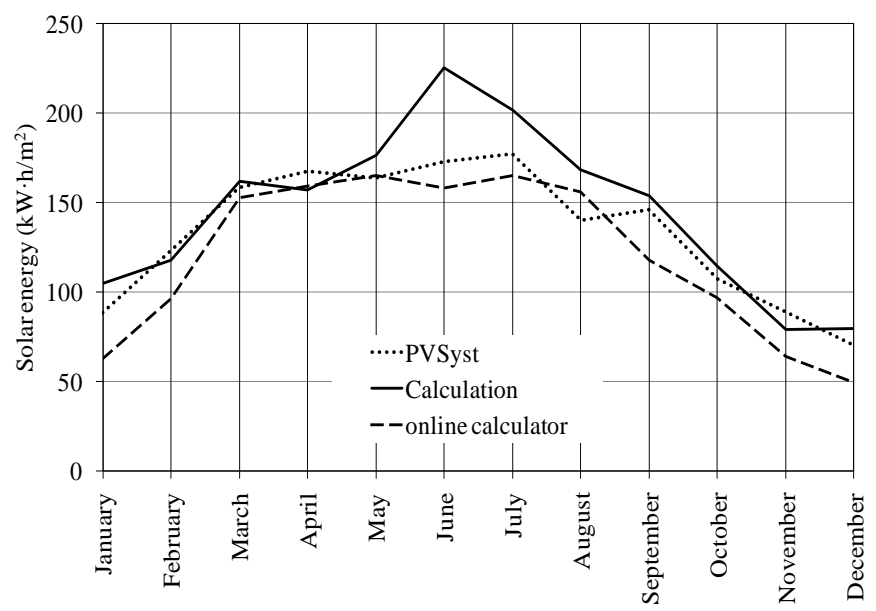

Рис. 4. Comparison of results of modeling of incoming solar radiation on the inclined plane.

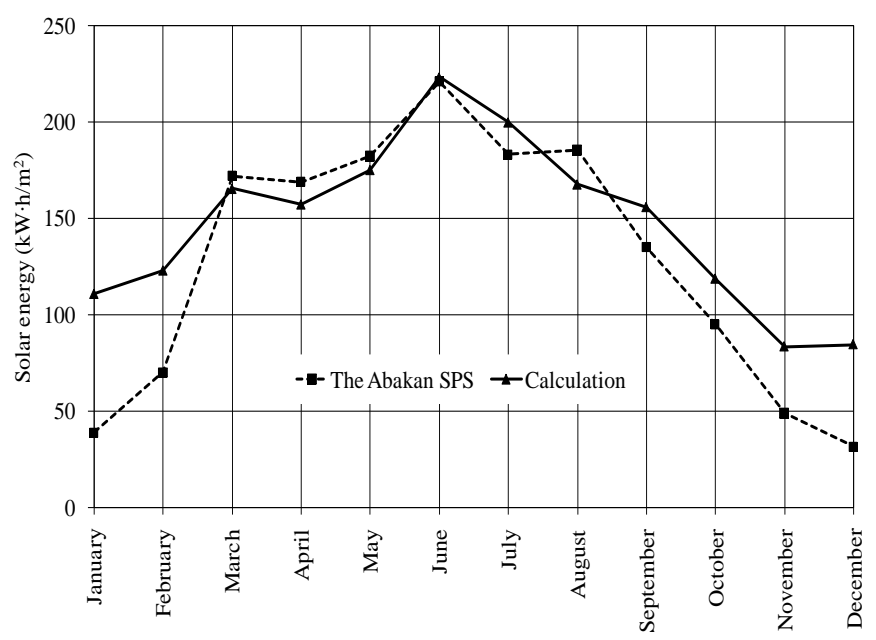

Рис. 5. Comparison of results of modeling with graph of electricity generation of the Abakan SPS.

By means of the considered model the graph of generation of electric power was received by solar batteries. In fig. 6 shows superimposed graphs of the power consumed by the object and the power generated by solar batteries for the same periods of time. The considered object works during a day shift. The graph of the power consumption of the object contains the peak area corresponding to the daytime. The design graph of solar panels generation is well combined with the graph of power consumption, which ensures the full use of the generated energy. At night, the electric power can be supplied from the centralized electrical network, the electric generator or from rechargeable batteries.

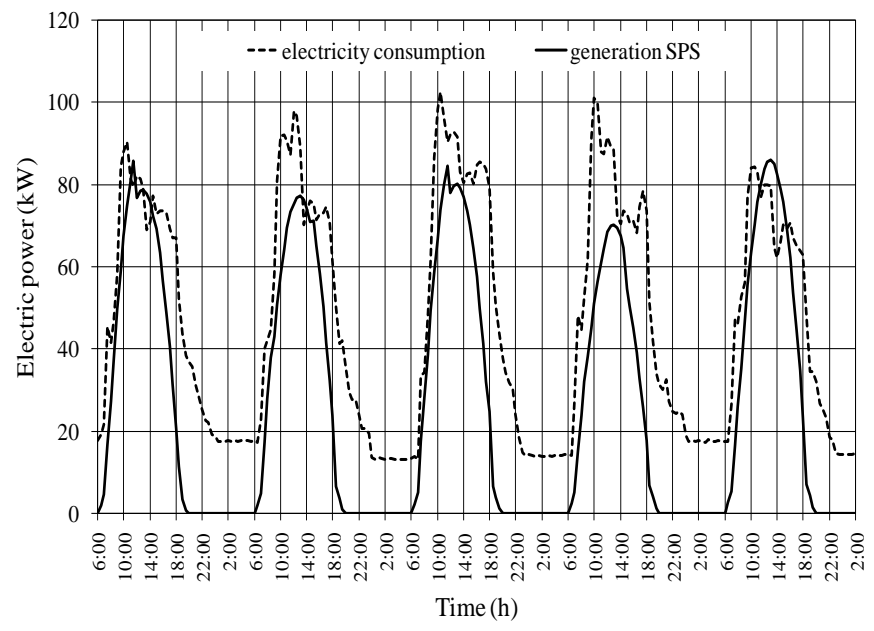

Рис. 6. Combined graphs of consumed and generated powers.

When using rechargeable batteries a peak part of the graph of generation should be above a peak part of the graph of consumption.

\section{CONCLUSIONS}

The review of methods of calculation of incoming solar energy on a surface of panels is executed. Advantages and shortcomings of a specialized software are considered.

As a result of study on the basis of the known formulas the technique of modeling of incoming solar energy on an inclined surface is made. The technique considers change of position of the sun on height and on an azimuth within a year with an interval of 0.5 hours. In calculations the direct and scattered solar radiation, a geographical location of panels, an inclination angle of panels to the horizon at orientation is considered to the south. Taking note of cloudiness as most significant factor is executed. Values of cloudiness can be received from contemporary records of the meteowebsites.

With use of mathematical model of incoming solar energy considerable influence of cloudiness on annual electricity generation of SPS is established. For the considered area the cloudiness leads to decrease in annual incoming solar energy on average twice in comparison with results of modeling for the clear sky. Because of influence of cloudiness in areas with the different longitude and identical latitude annual incoming solar energy can significantly differ. Comparison of results of modeling by means of the developed technique with calculation results by means of the existing programs yielded close results.

Modeling of incoming solar energy taking into account a factor of cloudiness allows to increase the accuracy of assessment of generation of SPS and its payback period. Modeling of the annual graph of incoming solar energy with an interval of 0,5 hours can be used together with real power graph of objects on which it is going to use solar panels. It will allow to more accurately select the power of solar panels and to exclude its incomplete use. 
On the basis of the conducted researches the following conclusions are drawn:

1) Accounting of a factor of cloudiness by means of statistics of long-term observations of local meteorological stations allows to increase significantly the accuracy of modeling of incoming solar energy on the surface of solar panels.

2) Comparison of results of modeling with real statistics of incoming solar energy on the site of the Abakan SPS was shown satisfactory accuracy.

3) Modeling in some cases allows to do without tool measurements of incoming solar energy on the surface of panels.

\section{References}

[1] L. Uniiat, «Economic efficiency of using solar energy in the agroindustrial business», Eureka: Social and Humanities, Osauhing «Scientific Route», no. 2, pp. 9-18, 2018. (In Estonia)

[2] A. V. Bayshev, A. S. Toropov, «Operation in Parallel with Network of Solar Electric Generating Stations of Private Houses», Bulletin of the Khakass State University named after NF Katanov, no. 19, pp. 8-9, 2017. (In Russia)

[3] A. V. Bayshev, A. S. Toropov, «Evaluation of the effectiveness of the tracking system for a solar power station», International Scientific and Practical Conference: Scientific and practical problems and directions of their solutions in the field of high technologies, Saratov, pp. 154-156, July 13, 2017. (In Russia)

[4] A. V. Bayshev, A. S. Toropov, «Parallel work with the power grid of solar power stations of private residential houses», International Scientific and Practical Conference: Science, Education and Innovation, Kazan, pp. 106-107, July 12, 2017. (In Russia)

[5] B. N. Sharifov, B. M. Gaisin, F. R. Ismagilov, T. R. Teregulov, N. L. Babikova, «Research of parallel operation of solar power plants to the network», Ufa State Aviation Technical University (UGATU), vol. 20, no. 4(74), pp. 71-79, 2016. (In Russia)

[6] N.V. Linder, E. V. Arsenova, «Cross subsidizing in power industry: theoretical approaches to definition and the analysis of dynamics of volumes», Economic Sistems, vol. 10, no 2(37), pp. 69-74, 2017. (In Russia)

[7] I. A. Dolmatov, I. Iu. Zolotova, «The cross subsidization in the electric power industry. what is the limit of growth?» Strategic decisions and riskmanagement, St. Petersburg, no. 2 (105), pp. 16-20, 2018. (In Russia)
[8] B. S. William, M. Geyer, «Power From The Sun», [online] Available: https://powerfromthesun.net

[9] V. I. Vissarionov, G. V. Deryugina, V. A. Kuznetsova, N. K. Malinin, «Solar energy. Calculation methods», Moscow, Solar Energy, 2008, 317 p. (In Russia)

[10] Irwan M., Amelia A.R., Irwanto M., Fareq M, Leow W.Z., Gomesh N., Safwati I. Stand-Alone Photovoltaic (SAPV) System Assessment using PVSYST Software // Energy Procedia: Elsevier. 2015, November, vol. 79, pp. 596-603. (In Netherlands)

[11] Kumar N.M., Kumar M.R., Rejoice P.R., Mathew M. Performance Analysis of $100 \mathrm{kWp}$ Grid connected Si-poly Photovoltaic System using PVSYST Simulation Tool», Energy Procedia: Elsevier. 2017, June, vol. 117, pp. 180-189. (In Netherlands)

[12]. T. Gurupira, A. Rix, «PV simulation software comparisons: pvsyst, nrel sam and pvlib» // Conference: SAUPEC, february 3, 2017, [online] Available: https://www.researchgate.net.

[13] Online calculator of generation, [online] Available: http://www.helioshouse.ru/on-line-kalkulyator.html

[14]. Sivkov S.I. Methods for calculating the characteristics of solar radiation. L.: Gidrometeoizdat, 1968. 185 p. (In Russia)

[15] I.N. Rusin. «Influence on the calculation of the insolation of errors in determining the position of the sun», Scientific notes of the Russian State Hydrometeorological University. Scientific and theoretical journal. St. Petersburg, no. 15 pp. 33-43, 2010. (In Russia)

[16] V. A. Shakirov, A. Y. Artemyev, «Technique for considering the influence of cloudiness on the solar radiation flux according to the archives of meteorological stations», Systems. Methods. Technologies. Bratsk, no. 4 (24) pp. 79-83, 2014. (In Russia)

[17] Weather in 243 countries, [online] Available: https://rp5.ru/.

[18] Weather Russia website, [online] Available: http://meteo.infospace.ru.

[19] B. I. Nazarov, M. A. Saliev, A. N. Mahmoudov, S. F. Abdullaev, "Calculation of the total radiation flux on the inclined plane of the solar receiver on condition of aerosol pollution of the atmosphere», Reports of the Academy of Sciences of the Republic of Tajikistan, Dushanbe, no. 12, vol. 58, pp. 1111-1118, 2015.

[20] A. Aculinin, V. Smicov, «Evaluation of opportunities of solar energetics on the basis of accurate ground-based measurements of solar radiation», Problems of regional energy, no. 1, pp. 29-39, 2008. (in Moldova)

[21] Association «Non-Profit Partnership Market Council», [online] Available: https://www.np-sr.ru/ru. 